Railway Engineering

Jan. 2022

Issue:15, Page: 46-59

Research Article

doi: 10.47072/demiryolu.1015962

http://dergipark.org.tr/demiryolu

e-ISSN: 2687-2463, ISSN: 2149-1607

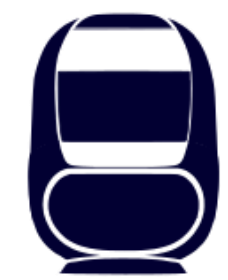

\title{
DCGAN ve Siyam Sinir Ağını Kullanarak Demiryolu Bağlantı Elemanlarındaki Kusurların Tespiti
}

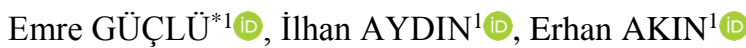 \\ ${ }^{1}$ Fırat Üniversitesi, Mühendislik Fakültesi, Bilgisayar Bölümü, Elazı̆̆, Türkiye \\ *emreguclu1367@gmail.com
}

(Alınış/Received: 28.10.2021, Kabul/Accepted: 18.12.2021, Yayımlama/Published: 31.01.2022)

\begin{abstract}
Öz: Bağlantı elemanlarındaki kusurların tespiti, demiryolu denetiminin önemli bir parçasıdır. Bu nedenle son yıllarda, bağlantı elemanlarının hızlı ve güvenilir bir şekilde denetlenebilmesi için otomatik denetim sistemlerine ihtiyaç duyulmaktadır. Otomatik denetim sistemlerinde derin öğrenme gibi yöntemler kullanılmaktadır. Ancak bu tür yöntemler, eğitim için çok fazla veri setine ihtiyaç duyarlar. Geleneksel bir evrişimli sinir ağı küçük bir veri seti ile özellikleri öğrenemez. Eğitim işlemi için sağlam bağlantı elemanlarından oluşan veri setini oluşturmak kolay olmasına rağmen kusurlu bağlantı elemanlarından oluşan veri setini oluşturmak oldukça zordur. Bu tür veri setini oluşturmak için yüzlerce kilometre demiryolundan görüntü toplanması gerekebilir. Bu nedenle bu çalışmada, DCGAN kullanılarak yapay deforme bağlantı elemanı görüntüleri oluşturulup veri seti çoğaltılmıştır. Ardından, siyam sinir ağı ile bağlantı elemanlarının kusur durumu incelenmiştir. Çalışmada, sağlam ve deforme olmak üzere iki bağlantı elemanı sınıfı bulunmaktadır. Her sınıf için farklı sınıfların görüntüleri arasındaki benzerlik puanları hesaplanmıştır. Temel fikir, bağlantı elemanlarını benzerlik puanlarını kullanarak ve karşıllaştırma yaparak tanımlamaktır. Deneysel sonuçlarda, önerilen yöntem için \%98,23 doğruluk oranı elde edilerek, geleneksel yöntemlere göre avantajı gösterilmiştir.
\end{abstract}

Anahtar kelimeler: Siyam Sinir Ağı, Bağlantı Elemanı, Kusur Tespiti

Detection of Defects in Railway Fasteners Using DCGAN and Siamese Neural Network

\begin{abstract}
Detection of defects in fasteners is an important part of railway inspection. Therefore, in recent years, automatic inspection systems are needed for fast and reliable inspection of fasteners. Methods such as deep learning are used in automatic control systems. However, such methods require a lot of datasets for training. A traditional convolutional neural network cannot learn features with a small dataset. Although it is easy to generate a dataset of solid fasteners for training, it is quite difficult to generate a dataset of defective fasteners. It may be necessary to collect images from hundreds of kilometers of railroad tracks to create this type of dataset. For this reason, in this study, artificial deformed fastener images were created using DCGAN and the dataset was reproduced. Then, the defect status of the connectors with the siamese neural network was examined. In the study, there are two fastener classes as healty and deformed. Similarity scores between images of different classes were calculated for each class. The basic idea is to identify fasteners using similarity scores and comparing. In the experimental results, $98,23 \%$ accuracy rate was obtained for the proposed method and its advantage over traditional methods was demonstrated.
\end{abstract}

Keywords: Siamese Neural Network, Fastener, Defect Detection

\section{Giriş}

Ray bağlantı elemanları, rayları travers ile birlikte alttaki taban plakasına sabitlemek ve titreşimi azaltmak için kullanılır. Bağlantı elemanları demiryollarında çok sayıda bulunur. Bu nedenle, demiryolu bağlantı elemanları güvenliği etkileyen çok önemli bir bileşendir [1]. Uzun süreli çalışmalarda trenin geçişi sırasında oluşan ağırlık ve titreşim bağlantı elemanlarında hasara sebep

Atıf için/Cite as: E. Güçlü, İ. Aydın, E. Akın, "DCGAN ve siyam sinir ağını kullanarak demiryolu bağlantı elemanlarındaki kusurların tespiti , ” Demiryolu Mühendisliği, no. 15, pp. 46-59, Jan. 2022 doi: 10.47072/demiryolu.1015962 
olabilir. Hasar görmüş bağlantı elemanları trenlerin güvenliğini önemli ölçüde tehdit edecektir. $\mathrm{Bu}$ nedenle bağlantı elemanları, demiryolu denetiminde periyodik olarak kontrol edilmelidir. $\mathrm{Bu}$ bileşenlerin sürekli denetlenmesi, güvenli bir demiryolu ortamının oluşmasını sağlar ve meydana gelebilecek kazaların önlenmesi açısından büyük önem taşır.

Geleneksel olarak demiryolu denetimi görsel olarak yapılmaktadır. Ancak görsel incelemenin öznel, maliyetli, yavaş olması ve denetim esnasında rayı meşgul etmesi gibi dezavantajları vardır. Ayrıca, demiryolundan toplanan görüntüler, saatlerce süren video kayıtlarından elde edilmektedir. Bu devasa miktardaki veri, görüntüleri manuel olarak incelemeyi ve kusur tespitini oldukça zorlaştırmaktadır. $\mathrm{Bu}$ nedenle son yıllarda bazı araştırmacılar, otomatik inceleme yöntemleri üzerinde çalışmalar yapmaktadır [2]. Yapılan çalışmalarda, hata tespiti için bilgisayarlı görme ve makine öğrenimi tabanlı teknikler uygulanmaktadır. Özellikle, görüntü işlemeye dayalı teknikler sıklıkla kullanılmaktadır. Bağlantı elemanı algılama yöntemleri üzerine yapılan araştırmalar, temel olarak görüntü toplama ve işleme üzerine odaklanmıştır [3-4].

Son yıllarda görüntü işleme tekniklerinin yanı sıra derin öğrenme gibi teknikler de sıklıkla kullanılmaya başlandı. Yakın zamana kadar bilgisayar algoritmaları insan görsel denetimine yaklaşamıyordu. Ancak, bu durum derin öğrenme mimarilerinin geliştirilmesiyle birlikte değişti [5]. Kusur tespitinde derin öğrenmenin kullanılması insan hatasını azaltabilir ve uzun süreli çalışmaya uygundur. Yapılan çalışmalarda derin öğrenme tekniklerinin doğru bir şekilde uygulandıkları takdirde kusur tespiti için iyi performans gösterdiği ispatlanmıştır. Derin öğrenme teknikleri, kusur tespitinde gösterdikleri performanstan dolayı birçok kusur tespit alanında kullanılmaktadır. Bunlar arasında; döküm hatalarının tespiti [6], ahşap kaplama kusur tespiti [78], fotovoltaik panellerde bulunan kusurların tespiti [9], yüzey kusur tespiti [10] bulunmaktadır. Ayrıca, demiryollarında bulunan bağlantı elemanlarındaki kusurları da tespit için derin öğrenmeye dayalı yöntemler kullanılmaktadır.

Faghih-Roohi vd. [11] yaptıkları çalışmada, ray yüzeyindeki kusurların tespiti için Derin Evrişimli Sinir Ağı (DCNN) kullanmışlardır. Wei vd. [12], bağlantı elemanlarının durumu için gelişmiş bir YOLOv3 modeli önermişlerdir. Cui vd. [13]'te, bağlantı elemanlarının kontrolü için nokta bulutu derin öğrenme tabanlı yöntem önermişlerdir. Bai vd. [14]'de, bağlantı elemanı tespiti için değiştirilmiş Daha Hızlı Bölge Tabanlı Evrişim Sinir Ağı (Faster R-CNN) ve Destek Vektör Veri Tanımı (SVDD) algoritmalarına dayanan iki aşamalı bir sınıflandırma modeli önermiştir.

Güçlü vd. [15]'te, bağlantı elemanlarındaki kusurları YOLOv4 ve bulanık mantık kullanılarak tespit etmiştir. Ou vd. [16]'da, bağlantı elemanlarını normal, kısmen aşınmış, eksik ve kapalı olmak üzere dört tipe ayırabilen bir bağlantı elemanı sınıflandırma modeli önermiştir. Liu vd. [17]'de, bağlantı elemanlarının kusur durumlarını otomatik algılamayı sağlamak için DCNN'e dayalı bir inceleme modeli önermiştir. Ayrıca çalışmada, kusurlu bağlantı elemanlarının zor bulunması nedeniyle kusurlu ve sağlam bağlantı elemanları arasındaki dengesizliği önlemek için veri setini büyütmek amacıyla sağlam bağlantı elemanlarından kusurlu bağlantı elemanları üretilmiştir.

Bu çalışmada, demiryolu bağlantı elemanlarında oluşabilecek kusurların tespiti için siyam ağlarına dayalı bir teknik sunulmuştur [18]. Çalışmanın amac1, yapısı bozulan bağlantı elemanlarını siyam sinir ağı ile tespit etmektir. Siyam sinir ağı, giriş görüntülerinin benzerliğini hesaplamak için çok kullanışlı olan iki özdeş sinir ağına dayanan bir bağlantı çerçevesidir. Kullanılan siyam ağı, eğitim verisi gereksinimlerini önemli ölçüde azaltarak bağlantı elemanlarında bulunan kusurları etkin bir şekilde tanımayı sağlamaktadır.

Siyam ağlarının iki kanallı yapısı, eğitim için çok sayıda örneğe olan bağımlılığı azaltır. Geleneksel sinir ağlarından farklı olarak bu yöntemde farklılıklar, tek bir görüntüden değil belirli 
yapısal benzerlikler içeren görüntü çiftlerinden öğrenilir. Bu yaklaşımda, kusurlu veya sağlam sınıfına ait birkaç görüntüyle bile kusurlu bağlantı elemanını etkin bir şekilde tespit edebilmektedir. Siyam sinir ağlarını kullanarak kusur tespiti ile ilgili çeşitli çalışmalar yapılmıştır. Çelik yüzeylerde bulunan kusurların tespiti [19], düğmelerdeki kusurların tespiti [20], trafik işaretlerindeki kusurların tespiti [21] bu çalışmalara örnek olarak verilebilir.

Siyam ağında kullanılacak veri kümesini, eğitim için yeterli hale getirebilmek için deforme bağlantı elemanlarının yeterli sayıda olması gerekmektedir. Deforme bağlantı elemanı görüntülerinin yapay olarak üretilmesi ile yeterli eğitim verisi oluşturulabilir. Yapay görüntü üretimi bilgisayarla görmede önemli bir sorundur. Gerçek görüntülerden oluşturulan yapay bağlantı elemanı görüntüleri, daha çeşitli eğitim sonuçları elde etmek için kullanılabilir. Son yıllarda, çekişmeli üretici ağlar (GAN), görüntü oluşturma uygulamalarına başarıyla uygulanmıştır [22]. Yeni bir görüntü oluşturma modeli türü olan GAN'lar, giderek gelişmektedir ve DCGAN, CGAN, Pix2Pix gibi çok sayıda türü bulunmaktadır. Bu çalışmada, yapay bağlantı elemanı görüntüsü üretmek için Derin Evrişimli Çekişmeli Üretici Ağlar (DCGAN) kullanımı önerilmiştir. Ardından, veri setini büyütmek ve bağlantı elemanlarının durumları hakkında bilgi almak için üretilen yapay görüntüler gerçek görüntülerle birleştirilmiştir.

Makalenin geri kalanı şu şekilde düzenlenmiştir: Bölüm 2'de önerilen yöntem açıklanmıştır. 2.1'de kullanılan veri kümesi tanitılırken, 2.2'de veri kümesine uygulanan görüntü önişleme algoritması açıklanmıştır. 2.3'te çeşitliliği artırmak için DCGAN algoritması kullanılarak yapay veri oluşturulmuştur. 2.4 'te siyam ağ 1 modeli tanıtılırken, deneyler ve değerlendirmeler Bölüm 3 'te verilmiştir. Sonuç bölümünde ise değerlendirmeler yapılmıştır.

\section{Materyal ve Metot}

Yaklaşımımız, kusur tespiti için iki katmanlı bir sinir ağı oluşturmaktır. Önerilen bu yöntemde, geleneksel sinir ağlarından farklı olarak farklılıklar tek bir görüntüden ziyade belirli yapısal benzerlikler içeren görüntü çiftlerinden öğrenilir. Kusur tespiti için ikili bir Siyam sinir ağı kullanılmıştır. Veri kümesi, DCGAN ile üretilen yapay görüntülerle genişletilerek Siyam ağının başarımı artırılmıştır.

\subsection{Kullantlan veri kümesi}

Veri kümesi Türkiye Cumhuriyeti Devlet Demiryolları Araştırma Merkezi (DATEM) tarafından bir ölçüm treni üzerinden elde edilen görüntülerden oluşturulmuştur (Şekil 1). Bu çalışmada, bağlantı elemanlarındaki kusur tespiti incelendiği için bağlantı elemanlarından oluşan veri kümesi elde edilmiştir. $\mathrm{Bu}$ amaçla, ölçüm treni tarafindan elde edilen görüntüler üzerinden bağlantı elemanı görüntüleri, manuel olarak kırpılarak elde edilmiştir. Veri kümesinde, eğitim için 400 sağlam ve 400 kusurlu olmak üzere toplam 800 adet bağlantı elemanı görüntüsü bulunmaktadır. Bu görüntülere yapay bağlantı elemanı görüntüleri dâhildir. Kusurlu bağlantı elemanı görüntüleri kırık veya eğilmiş bağlantı elemanı görüntülerinden oluşmaktadır. Test için ise 100 sağlam ve 100 kusurlu olmak üzere toplam 200 bağlantı elemanı görüntüsü vardır. Veri kümesi toplamda 1000 görüntüden oluşmaktadır ve bulunan her örnek görüntünün çözünürlüğü $227 \times 227$ pikseldir.

Test görüntülerinde yapay görüntü bulunmamaktadır. Buradaki amaç, yapay olarak üretilen bağlantı elemanlarını eğitimde kullanarak gerçekten kusurlu bağlantı elemanlarını tespit edebilmektir. 


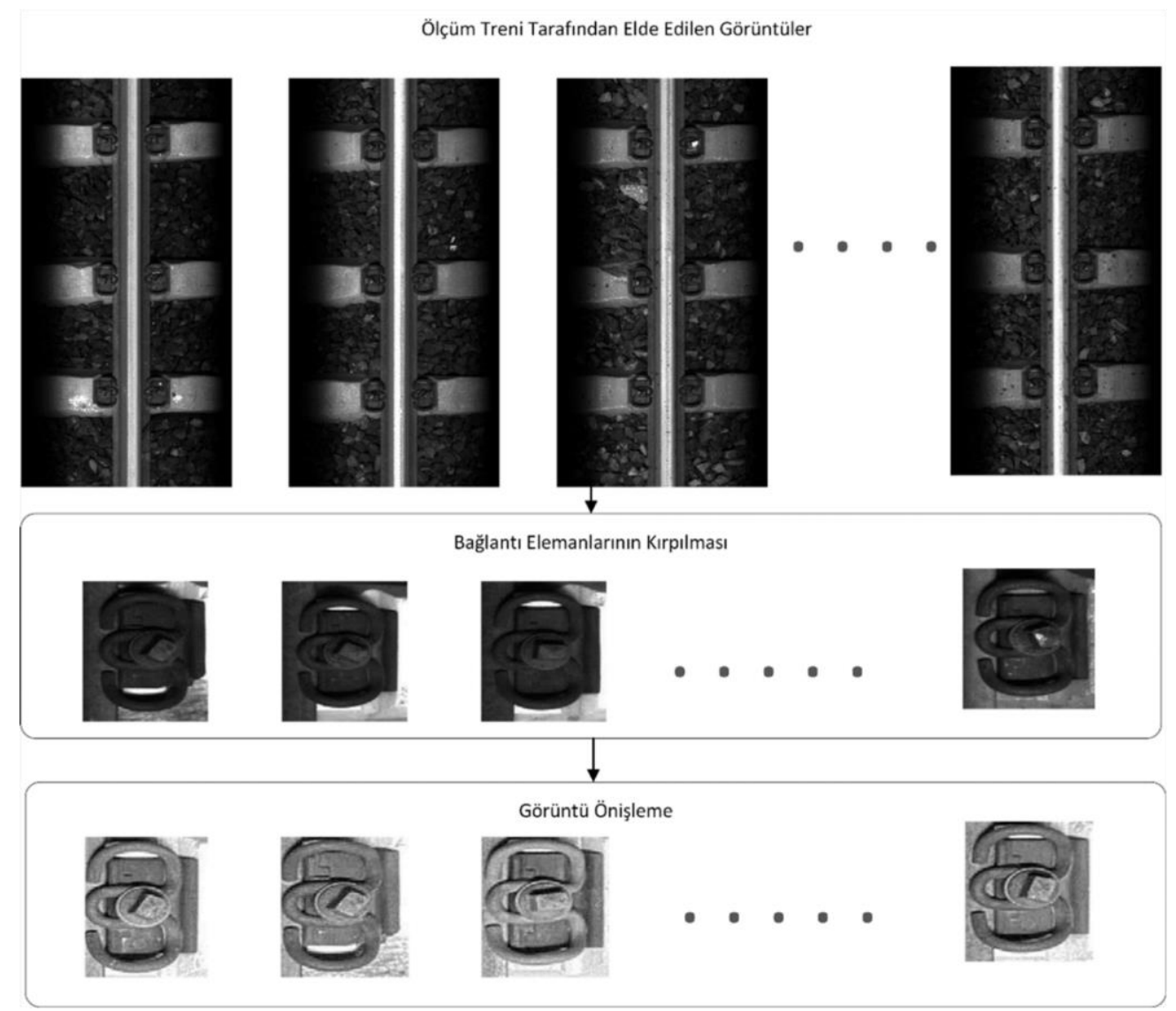

Şekil 1. Ölçüm treninden elde edilen görüntülerden bağlantı elemanı veri kümesinin oluşturulması

\subsection{Görüntü önişleme}

Ölçüm treninden alınan görüntüler, parlak olmadığından tanıma görevi için dezavantaj oluşturmaktadır. Bu dezavantajın üstesinden gelebilmek için veri kümesinde bulunan görüntülere görüntü iyileştirme işlemi uygulanmıştır. Bu çalışmada kullanılan görüntü iyileştirme algoritması, [23]'e dayanmaktadır. Görüntülere uygulanan algoritma, giriş olarak düşük 1şıklı görüntüyü alır. İlk olarak alınan görüntünün tersi alınır ve ardından ters çevrilmiş videoya optimize edilmiş bir görüntü bulanıklığg giderme algoritması uygulanarak daha net görüntüler elde edilir. Bu nedenle, giriş olarak alınan düşük görüntü I için ilk olarak aşağıdaki denklem kullanarak ters çevirme işlemi yapıılır.

$$
R^{c}(x)=255-I^{c}(x)
$$

Denklem 1'de c renk kanalı, $I^{c}(x)$, düşük aydınlatmalı görüntüyü temsil eden I'nın piksel x'in renk kanalının yoğunluğu ve $R^{c}(x)$, ters çevrilmiş görüntü olan $\mathrm{R}$ ile aynı yoğunluğu ifade etmektedir. Elde edilen görüntüye Denklem 2'de verilen denklem kullanılarak bulanıklık kaldırma uygulanmaktadır [24].

$$
R(x)=J(x) t(x)+A(1-t(x))
$$

Burada A, küresel atmosferik 1şıktır. $R(x)$, kameranın yakaladığı piksel x'in yoğunluğudur. $J(x)$, orijinal nesnelerin veya sahnenin yoğunluğudur. $t(x)$,nesnelerden veya sahneden yayılan 1şığın yüzde kaçının kameraya ulaştığıdır. Atmosfer homojen olduğunda, $t(x)$ şu şekilde ifade edilebilir: 


$$
t(x)=e^{-\beta d(x)}
$$

Burada $\beta$ atmosferin saçılma katsayısı ve $\mathrm{d}(\mathrm{x})$ piksel $\mathrm{x}$ 'in sahne derinliğidir. $\beta$ 'nın sabit olduğu aynı görüntüde, $\mathrm{t}(\mathrm{x})$, nesne ile kamera arasındaki mesafe olan $\mathrm{d}(\mathrm{x})$ tarafindan belirlenir. [23]'e göre $J(x)$ Denklem 4'teki gibi hesaplanmıştır:

$$
J(x)=\frac{R(x)-A}{P(x) t(x)}+A
$$

Denklem 4'e göre eğer $\mathrm{t}(\mathrm{x}) 0,5$ 'ten küçük ise, pikselin güçlendirilmesi gerektiği anlaşllır. $\mathrm{Bu}$ pikselin RGB yoğunluğu $P(x) t(x)$ 'i daha da küçültmek için $P(x)$ 'e daha küçük bir değer atanarak artırılır. Tersi durumda piksel yoğunluğu aşırı derecede artırılmaz. Görüntü iyileştirme işleminden sonra oluşturulan yeni veri kümesinden bazı örnek görüntüler Şekil 1'de verilmiştir.

\subsection{DCGAN ile ĕgitim görüntülerinin çoğaltılması}

Demiryollarından deforme bağlantı elemanı görüntülerinin toplanması zor bir görevdir. Kusur tespiti yapabilecek ağı eğitmek için yüzlerce veri gerekirken toplanan deforme bağlantı elemanı görüntü sayısı oldukça sınırlıdır. Bu nedenle, ağın başarımını artırmak için veri setinde deforme bağlantı elemanı görüntülerinin sayısının artırılması gerekmektedir. Derin öğrenme yapay görüntü üretiminde önemli bir araç olarak kullanılmaktadır [25]. Derin öğrenmenin görüntü üretiminde kullanımı ilk olarak Goodfellow [26] tarafından önerilmiştir. GAN yapısı bir adet üretici (generative) ve bir adet ayrıştırıcı (discriminator) olmak üzere iki farklı derin ağa sahiptir. Bu çalışmada, Derin Evrişimli Çekişmeli Üretici Ağlar (DCGAN) kullanılmıştır. DCGAN, çekişmeli üretici ağların alt dallarından biridir. DCGAN, denetimli öğrenme kullanan bir CNN ile denetimsiz öğrenme algoritması kullanan bir GAN'ı birleştirir [27]. DCGAN yapısı Şekil 2'de verilmiştir. DCGAN yapısında iki model, çekişmeli olarak aynı anda eğitilir. Eş zamanlı olarak eğitilen üretici ve ayrıştırıcı ağ olmak üzere iki bölümden oluşur. Ayrıştırıcı model, bir örneğin gerçek mi yoksa sahte mi olup olmadığını belirlemeye yöneliktir.

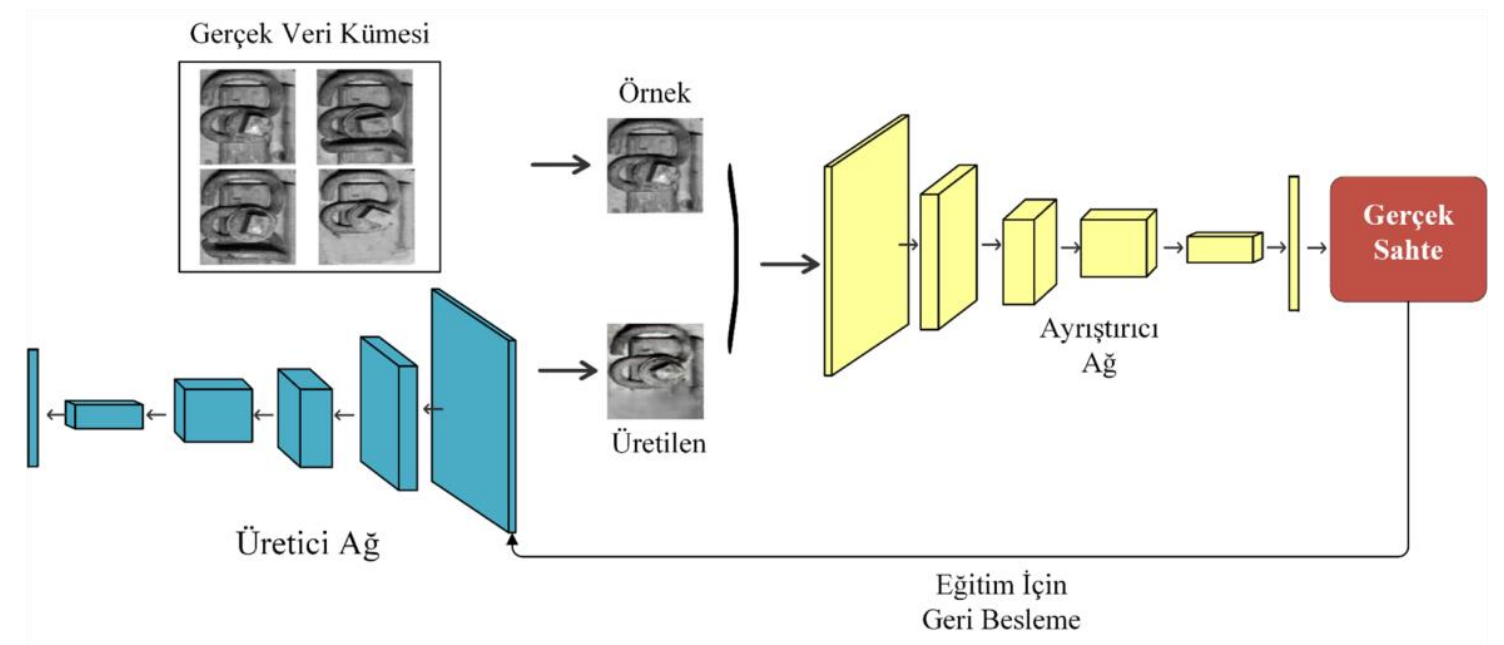

Şekil 2. DCGAN yapısı

Ayrıştırıcı model, eğitim sisteminde üretici modelin verilerini gerçekçi ve gerçekçi olmayan olarak sınıflandıran ikili bir sınıflandırıcıdır. DCGAN modelinin çekişmeli eğitim süreci Denklem 5 kullanılarak hesaplanır.

$$
\left.\operatorname{minmax}(D, G)=E_{x-p \operatorname{data}(x)}[\log D(x)]+E_{x-p(x)} \log [1-D(G(z)))\right]
$$


Üretici ağ gerçeğe en yakın görünen görüntüler yaratmayı öğrenirken, ayrıştırıcı ağ ise gerçek görüntüleri sahte olanlardan ayırmayı öğrenir. Eğitim sırasında sürekli geri besleme yapılır. Bu şekilde, üretici ağ giderek daha gerçek görünen görüntüler yaratır. Ayrıştırıcı ağ ise sahte görüntüler ile gerçek görüntüleri ayırt etmede daha iyi hale gelir. Bu süreç dengeye ulaştığında ayrıştırıcı artık gerçek görüntüleri sahtelerden ayırt edemez. Bu şekilde, en gerçekçi yapay görüntüler elde edilmiş olur. Üretici ağın ürettiği sonuçlar devir sayısına göre Şekil 3'te verilmiştir.
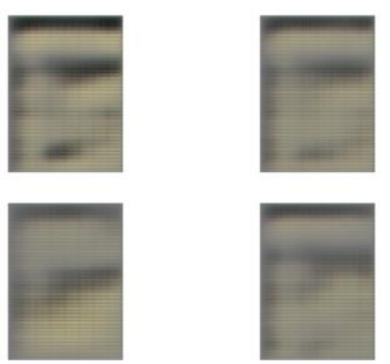

a) 50. döngü
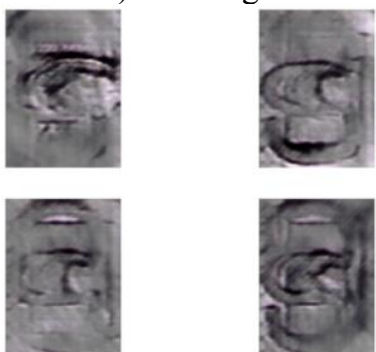

c) 200. döngü
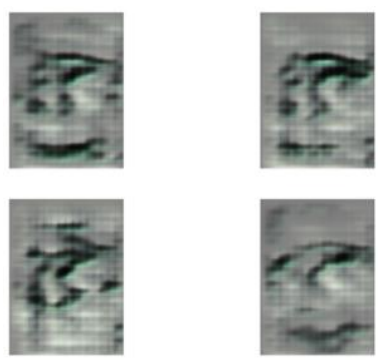

b) 100. döngü
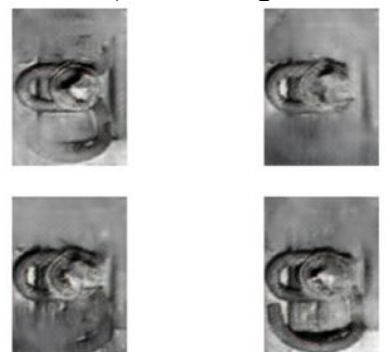

d) 350. döngü

Şekil 3. Eğitim aşamasında devir sayısına göre DCGAN ile üretilen bazı deforme bağlantı elemanı görüntüleri

DCGAN ile üretilen deforme bağlantı elemanları eğitim için kullanılmıştır. Buradaki amaç, eğitim için daha fazla deforme bağlantı elemanı örneği kullanarak doğruluğu artırmaktır. Toplam 300 adet yapay görüntü üretilmiştir. Hâlihazırda 100 adet deforme bağlantı elemanı bulunan veri kümesi 300 yapay görüntü ile birleştirilerek eğitim için 400 adet görüntü içeren deforme bağlantı elemanı veri kümesi oluşturulmuştur. DCGAN ile görüntü üretmek için kullanılan bazı deforme bağlantı elemanı görüntüleri ile üretilen görüntüler için bazı örnekler Şekil 4.a'da verilmiştir. DCGAN ile oluşturulan bazı yapay görüntü örnekleri ise Şekil 4.b'de verilmiştir.

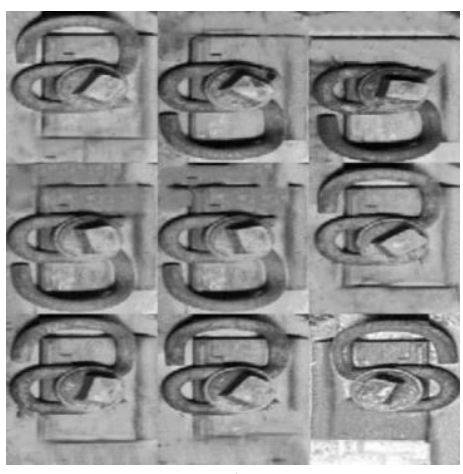

a)

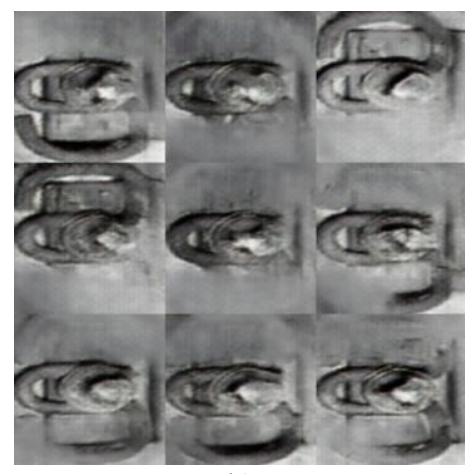

b)

Şekil 4. Oluşturulan deforme veri kümesi a) Görüntü üretimi için kullanılan veri kümesinden bazı deforme bağlantı elemanı görüntüleri b) Eğitim için kullanılmak üzere DCGAN ile üretilen görüntüler 


\subsection{Siyam ăğ modeli}

Siyam ağları, 90'ların başında bir görüntü karşılaştırmalı öğrenme problemi olan imza doğrulamasını gerçekleştirmek için Bromley vd. [28] tarafından önerilmiştir. Siyam ağları, diğer ağlara oranla güçlü ağlardır. Kullanım alanları arasında yüz tanıma ve imza doğrulama gibi alanlar vardır. Siyam sinir ağı, iki adet aynı alt ağ içeren bir sinir ağı mimarisi türüdür. Alt ağlar aynı parametreler ve ağırlıklarla aynı konfigürasyona sahiptir. Parametre güncellemeleri her iki alt ağa da yansıtılır. Siyam ağlarındaki ana fikir, giriş görüntülerinin verimli bir şekilde karşılaştırılması için gereken uygun benzerlik fonksiyonunu öğrenmektir. Siyam ağlarında sinir ağı, girdilerini sınıflandırmayı öğrenen bir model yerine, özellik vektörlerini kullanarak iki girdi arasında ayrım yapmayı öğrenir. İki adet aynı ağa sahip olduğu için girişte birbirine benzeyen görüntüler kullanıldığında fark fazla olmayacaktır. Farklı görüntüler kullanıldığında ise fark fazla olacaktır. Böylece, iki görüntünün aynı olup olmadığı tespit edilebilir. Siyam sinir ağının modeli Şekil 5'te verilmiştir. Bu iki alt ağ aynı mimariye ve parametrelere sahiptir. Bir alt ağdaki ağırlıklar güncellenirse diğer alt ağlardaki ağırlıklar da güncellenir. Bu alt ağlardaki son katmanlar olarak çıtılar arasındaki Öklid mesafesini hesaplayabildiğimiz ve alt ağların ağırlıklarını doğru kararı verecek şekilde ayarlayabildiğimiz katmanlardır.

Bu çalışmada, bağlantı elemanlarının kusurlu veya sağlam olup olmadığını araştırmak için siyam ağı kullanılmıştır. Siyam ağı sayesinde veri kümemizdeki her bağlantı elemanı görüntüsünü doğru bir şekilde sınıflandırmak için bir sınıflandırma modeli eğitmek yerine, eğitim setimizden iki görüntü alıp sinir ağına girdi olarak vererek aynı olup olmadığı belirlenecektir. Elde edilen benzerlik oranına göre iki bağlantı elemanının benzerliği belirlenecektir.

Şekil 5'teki diyagramda, sağlam ve deforme bağlantı elemanı görüntüleri, aynı ağırlık ve parametrelere sahip olan iki alt ağa girdi olarak verilir. Bu görüntüler, evrişimli katmanlardan geçtikten sonra görüntüler için özellik vektörleri elde edilir. Elde edilen h1 ve h2 özellik vektörleri, iki görüntünün ne kadar benzer olduğunu bilmek için karşılaştırılır. Karş1laştırma işlemi için özellik vektörleri arasındaki mesafe ölçülür. Aralarındaki mesafe küçükse vektörler benzerdir, mesafe büyükse vektörler farklıdır. Mesafe genellikle Öklid uzaklığ 1 ile ölçülür. Öklid formülü Denklem 6'da verilmiştir. Denklemde, x ve y modelin ürettiği iki vektörü ifade etmektedir.

$$
D=\sqrt{\sum_{i=1}^{n}\left(x_{i-} y_{i}\right)^{2}}
$$

Eğitim sırasında farklı hata fonksiyonları kullanılabilir. Hata fonksiyonunun amacı, ağın belirli bir görüntü çiftini ne kadar iyi ayırt ettiğini değerlendirmektir. Karşılaştırmalı hata fonksiyonu ve ikili çapraz entropi, siyam ağları için tercih edilen hata fonksiyonlarıdır. Bu çalışmada, hata fonksiyonu olarak ikili çapraz entropi kullanılmıştır. Amaç, girdilerin aynı sınıfta olup olmadığını sınıflandırarak çıktıda ikili sınıflandırma gerçekleştirmektir. İkili çapraz entropi'de kayıp şu şekilde hesaplanabilir:

$$
L=-y \log p+(1-y) \log (1-p)
$$

Burada L kayıp fonksiyonu, y sınıf etiketi (0 veya 1 ) ve p tahmindir. A ğı benzer ve farklı nesneler arasında ayrım yapmak üzere eğitmek için, her seferinde bir pozitif ve bir negatif örnek beslenebilir ve kayıplar toplanabilir. Bu kayıp işlevi, pozitif ve negatif kategorilerden bir eğitim örneği sağlanırsa ve her iki kayıp Denklem 8'deki gibi toplanırsa, benzer ve farklı görüntüler arasında ayrım yapabilmesi için ağı eğitmek için kullanılır. 


$$
L=L_{\text {pozitif }}+L_{\text {negatif }}
$$

Şekil 5'te görüldüğü gibi iki adet alt ağ olduğundan, siyam modeline iki girişimiz olmalıdır. Siyam ağlarını eğitirken aynı çiftlere ve farklı çiftlere ihtiyaç vardır. Aynı çiftler, aynı sınıfa ait iki görüntüyü ifade eder. Farklı çiftler ise farklı sınıflara ait iki görüntüyü ifade etmektedir. Siyam ağ1 eğitilirken, aynı ve farklı çift örnekleri rastgele seçilmiştir. Bu çiftler, siyam ağının benzerliği öğrenebilmesi için eğitim verileri olarak kullanılmaktadır. Pozitif çiftler aynı sınıfa ait iki ayrı görüntüden oluşmaktadır. Negatif çiftler ise farklı sınıflara ait iki görüntüden oluşmaktadır. Deforme bir bağlantı elemanı ile sağlam bağlantı elemanı negatif çift oluşturmaktadır. Sağlam iki bağlantı elemanı ise pozitif çift oluşturmaktadır.

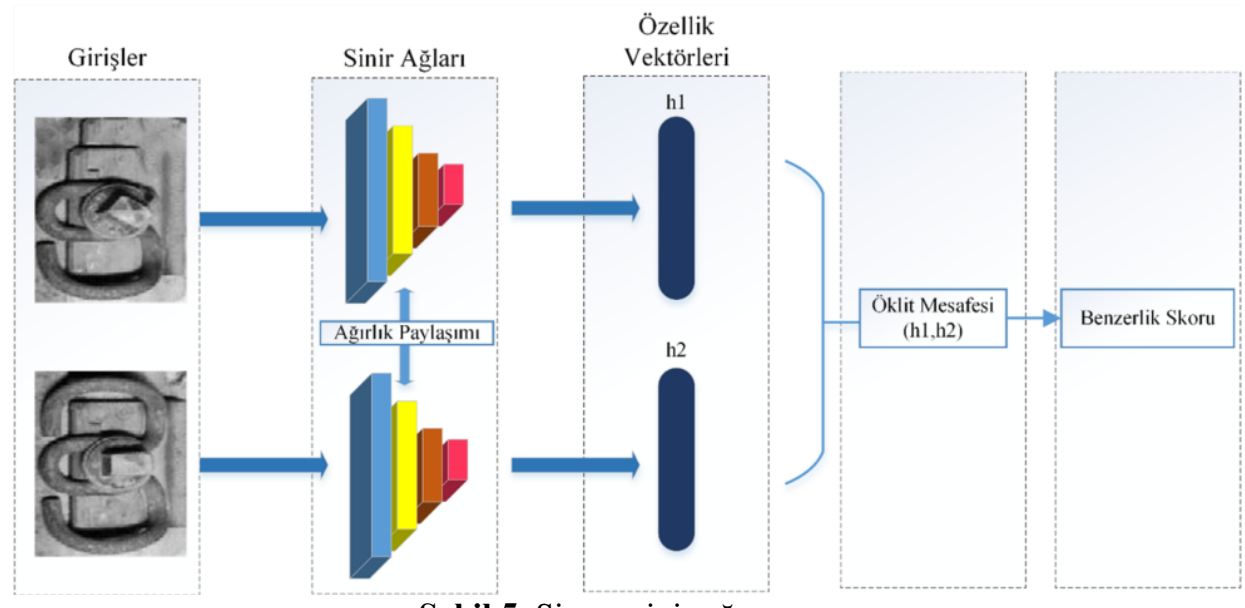

Şekil 5. Siyam sinir ağı yapısı

Siyam ağ1 eğitilirken, pozitif ve negatif çift örnekleri veri kümesinden rastgele örneklenir. Şekil 6 'da rastgele seçilen bazı görüntü çiftleri verilmiştir. Seçilen görüntüler, pozitif çift oluşturuyorsa benzer, negatif çift oluşturuyorsa farklı olarak nitelendirilmiştir.
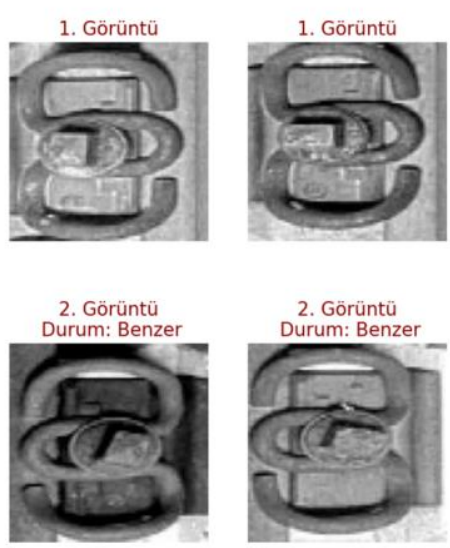
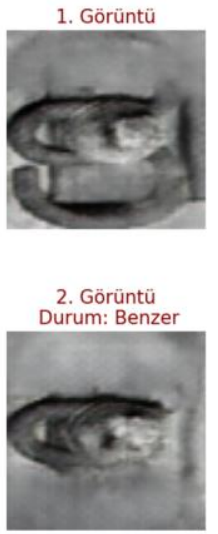
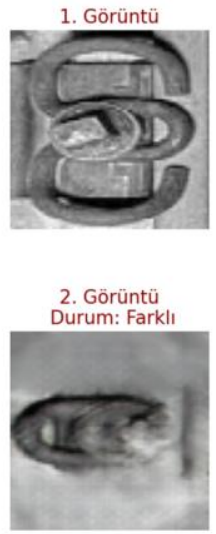
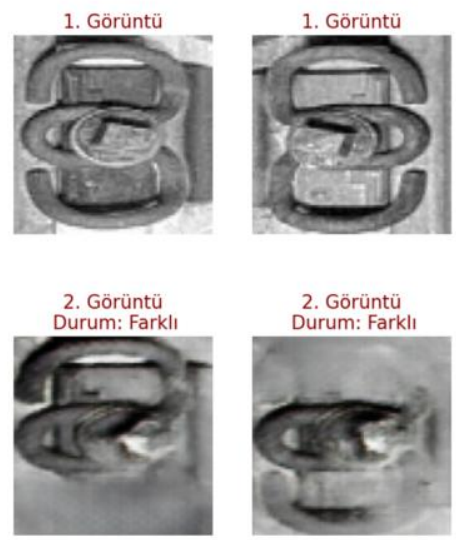

Şekil 6. Rastgele seçilen bazı görüntü çiftleri

Ağlar için giriş görüntülerinin uzamsal boyutları genişlik, yükseklik ve sayı kanalı şeklindedir. Veri kümemiz için giriş görüntüleri $75 \times 75 \times 3$ şeklindedir. Evrişimli sinir ağları, sınıflandırma ve özellik çıkarma kullanılır. Bu çalışmada, önerilen sinir ağı sınıflandırma için kullanılan sinir ağından farklıdır. Önerilen sinir ağının çıktısı bir özellik vektörüdür. Aktivasyon fonksiyonu 
olarak Relu [29] fonksiyonu kullanılmıştır. Siyam ağında kullanılan ağın yapısı Şekil 7'de verilmiştir.

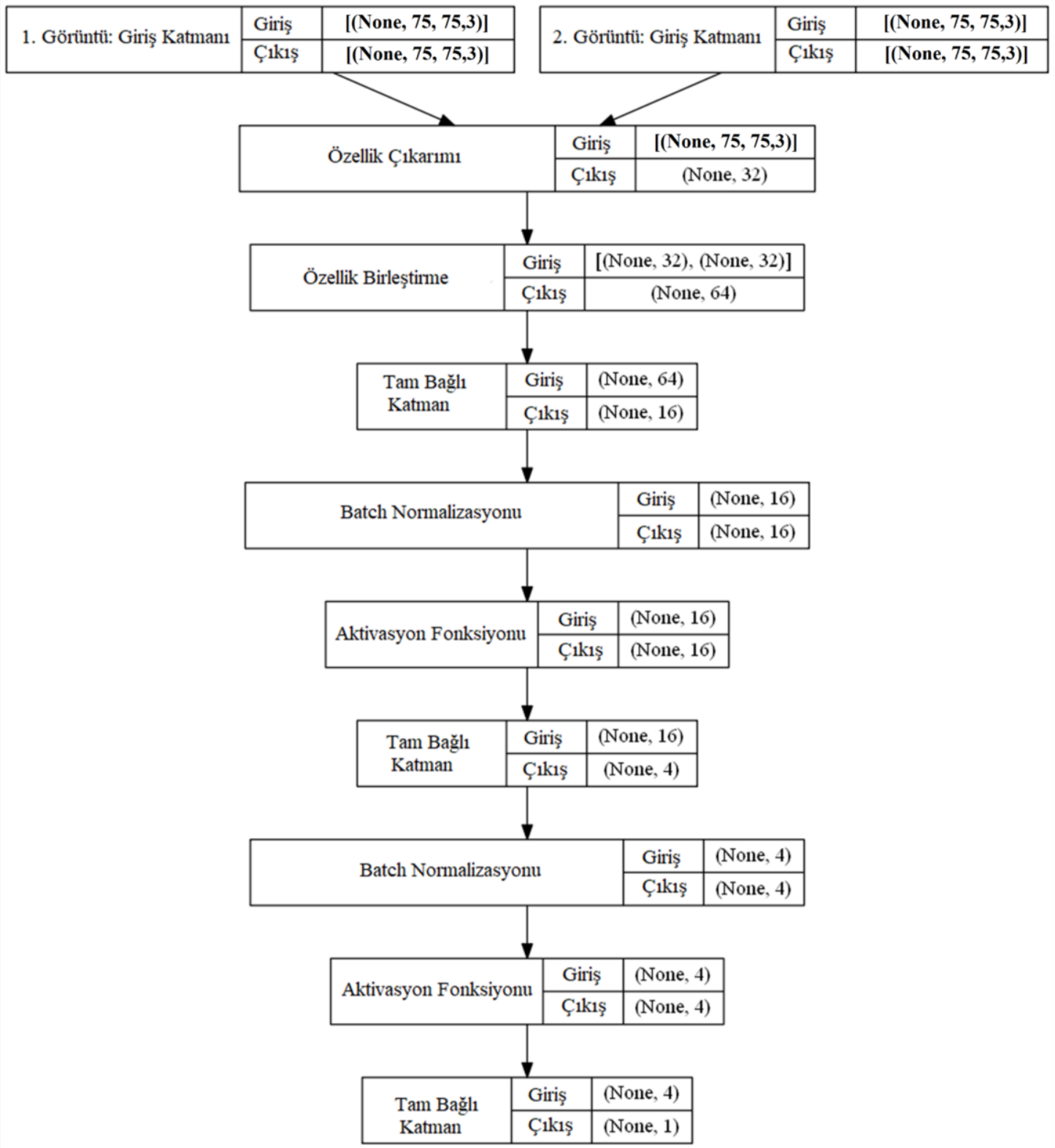

Şekil 7. Siyam sinir ağı modelinde kullanılan katmanlar ve parametreler

\section{Deneysel Sonuçlar}

Önerilen sinir ağı mimarisi, bağlantı elemanı görüntüsünün deforme veya sağlam olup olmadığını tahmin etmede kullanılmıştır. Yapılan deney, Windows 10 üzerine kurulu Python 3.8'de derlenmiştir. Önerilen algoritma TensorFlow çerçevesiyle uygulanmıştır ve model bir NVIDIA GeForce GTX 1060 kullanarak eğitilmiştir. Yöntemde batch değeri 32 olarak belirlenmiştir. Optimizasyon yöntemi olarak Adam Optimizer kullanılmıştır [30] ve öğrenme hızı 0,0001 olarak belirlenmiştir. Deforme ve sağlam olmak üzere iki sınıf ile öğrenme sağlanmıştır. Devir sayısı 100 olarak belirlenmiştir. Eğitim işlemi sonucunda oluşan eğitim ve test görüntülerinin başarım oranları Şekil 8 ve Şekil 9'da verilmiştir. 


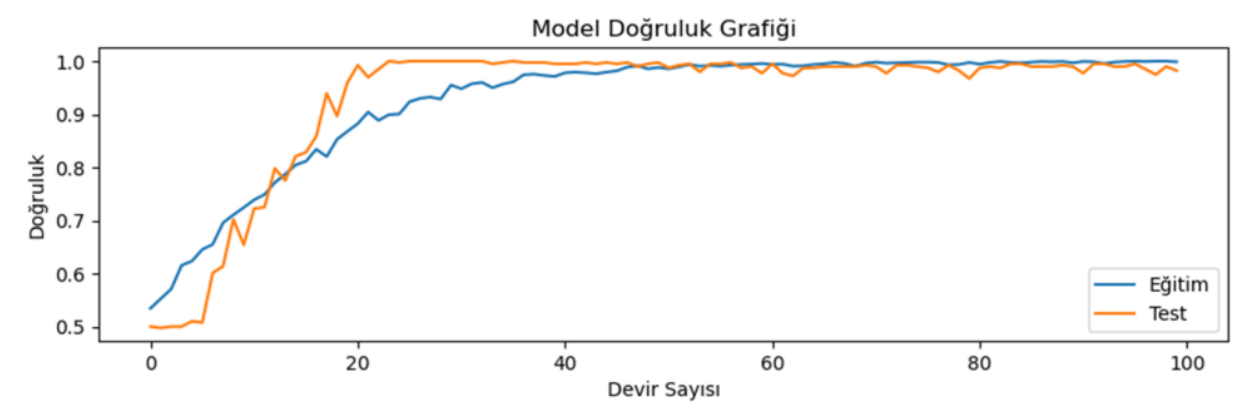

Şekil 8. Deney sonucunda oluşan model doğruluk grafiği

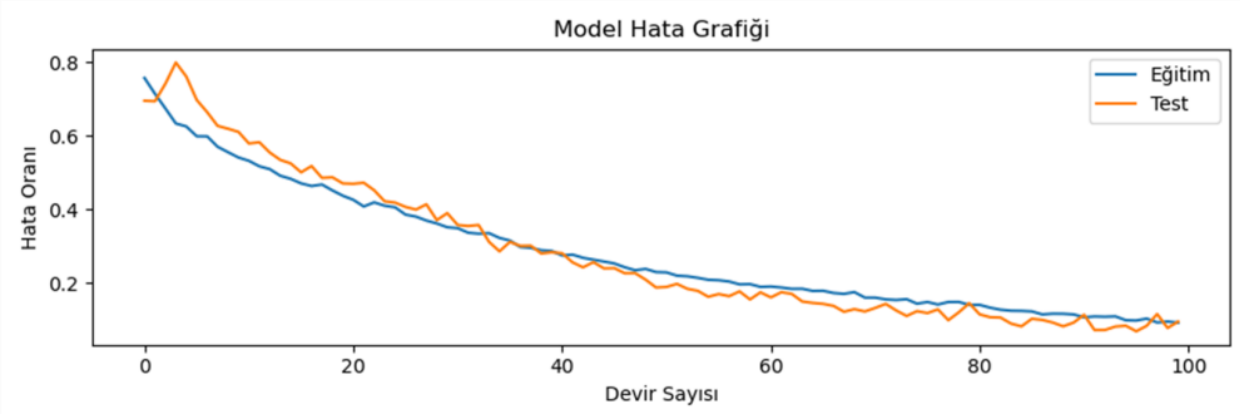

Şekil 9. Deney sonucunda oluşan model hata grafiği

Eğitim işlemi tamamlandıktan sonra eğitilmiş siyam ağı modeli iki görüntü çifti arasındaki benzerliği tahmin etmek için kullanılmıştır. Ağın son katmanında Sigmoid aktivasyon fonksiyonu kullanılmıştır. Sigmoid aktivasyon fonksiyonunun $[0,1]$ aralığında bir çıktısı vardır. Bu nedenle, siyam ağına bir görüntü girdi olarak verildiğinde çıkış değeri, 0 ile 1 arasında bir değer olacaktır. Elde edilen 0 değeri, iki görüntünün birbirinden tamamen farklı olduğu anlamına gelirken, 1 değeri, görüntülerin aşırı benzer olduğu anlamına gelir. Örnek olarak, deforme bağlantı elemanı ile sağlam bağlantı elemanı karşılaştırılırsa 0'a yakın bir değer elde edilirken, sağlam bağlantı elemanı ile başka bir sağlam bağlantı elemanını karşılaştırıldığında 1'e yakın sonuç elde edilir. $\mathrm{Bu}$ çalışmada, karşılaştırma sonucunda elde edilen çıkış değeri 100 ile çarpılarak benzerlik oranı yüzde cinsinden verilmiştir. Rastgele yapılan bazı karşılaştırma sonuçları Şekil 10'da verilmiştir. Şekil 10'da görüldüğü gibi tahmin değerleri gerçek değerlere yakın çıkmıştır. Eğer tahmin değeri \%50'nin altında ise görüntü farklı, \%50'nin üzerinde ise görüntüler aynı olarak belirlenmiştir. Test verilerindeki eşleştirme sayısı 396 olarak belirlenmiştir. Eşleştirmelerden elde edilen karmaşıklık matrisi sonucu Şekil 11'de verilmiştir.
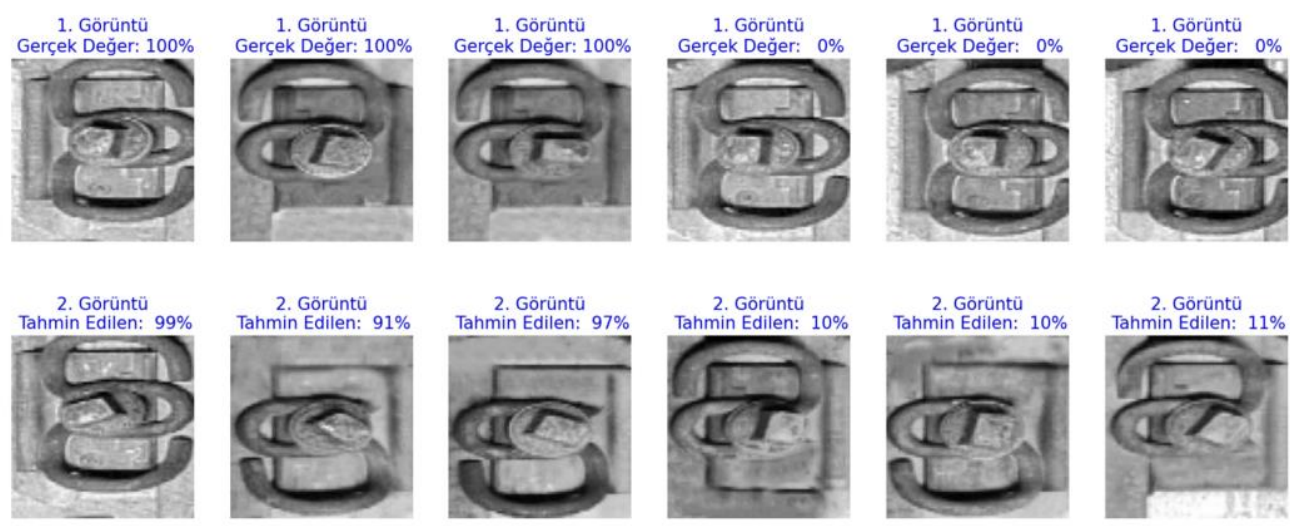

Şekil 10. Eğitilen siyam ağına göre iki görüntünün benzerlik oranına göre karşılaştırılması 
Karmaşıklık matrisi doğruluk, duyarlılık, özgünlük ve F1 değerlerini ölçmek için son derece kullanışlıdır. Bu değerleri hesaplamak için gerekli denklemler aşağıda sırasıyla verilmiştir.

$$
\begin{gathered}
\text { Doğruluk }=\frac{\mathrm{DP}+\mathrm{DN}}{\mathrm{DP}+\mathrm{YN}+\mathrm{YP}+} \\
\text { Duyarlılık }=\frac{\mathrm{DP}}{\mathrm{DP}+\mathrm{YN}} \\
\text { Kesinlik }=\frac{\mathrm{DP}}{\mathrm{DP}+\mathrm{YP}} \\
\mathrm{F} 1=\frac{2 \times \mathrm{DP}}{2 \times \mathrm{DP}+\mathrm{YP}+\mathrm{YN}}
\end{gathered}
$$

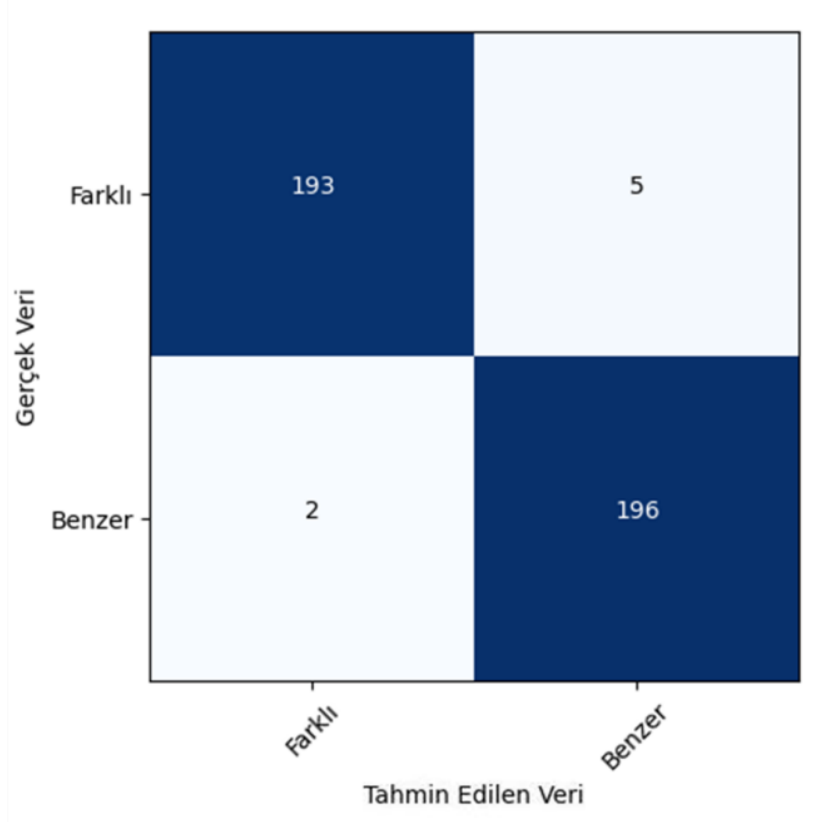

Şekil 11. Test görüntülerinin eşleştirilmesi sonucu oluşan karmaşıklık matrisi

Tablo 1. Önerilen yöntemin performans sonuçları

\begin{tabular}{cccc}
\hline Doğruluk (\%) & Duyarlılık (\%) & Kesinlik (\%) & F1 (\%) \\
\hline 98,23 & 98,98 & 97,51 & 98,25 \\
\hline
\end{tabular}

Önerilen yöntemin ölçüm sonuçları Tablo 1'de verilmiştir. Demiryolu bağlantı elemanlarının sınıflandırılmasında kullanılan mevcut yöntemler ile karşılaştırma sonuçları ise Tablo 2'de verilmiştir. Wei vd. [12]'de, algılama doğruluğunu ve verimliliğini artırmak için ölçek azaltma ve özellik birleştirmeyi entegre eden geliştirilmiş bir YOLOv3 modeli önermiştir. Bai vd. [14]'te, Faster R-CNN ve SVDD algoritmalarına dayanan iki aşamalı bir sınıflandırma modeli önerilmiştir. İlk olarak, Faster R-CNN'e dayalı sınıflandırma ve algılama modeli, pratik bağlantı elemanı görüntülerinin özelliklerine göre oluşturulmuştur. Daha sonra, Faster R-CNN tarafindan tespit edilen sonuca göre, eğilmiş bağlantı elemanlarının ikinci aşama sınıflandırması için SVDD 
algoritması uygulanmıştır. Böylece, bağlantı elemanlarının farklı eğim açılarından kaynaklanan yanlış sınıflandırma önlenmek istenmiştir. Güçlü vd. [15]'te, bağlantı elemanı görüntüleri 6 bölgeye bölünerek etiketlenmiştir. 6 parçaya YOLOv4 algoritması uygulanarak güven değerleri elde edilmiştir. Elde edilen güven değerleri, bulanık mantık yapısına giriş olarak verilerek sonuç elde edilmiştir. Ou vd. [16]'da, bağlantı elemanı görüntülerinden özellikler çıkarılarak destek vektör makinesi ile sınıflandırılmıştır.

Tablo 2. Performans sonuçlarının diğer yöntemlerle karşılaştırılması

\begin{tabular}{ccc}
\hline Referans & Kullanılan Yöntem & Doğruluk Oranı (\%) \\
\hline$[12]$ & Geliştirilmiş YOLOv3 modeli & 99,61 \\
{$[14]$} & $\begin{array}{c}\text { Faster R-CNN ve Destek } \\
\text { Vektör Veri Tanımı (SVDD) }\end{array}$ & 89,90 \\
{$[15]$} & $\begin{array}{c}\text { YOLOv4 ve bulanık mantık } \\
\text { tabanlı yöntem }\end{array}$ & 99,25 \\
{$[16]$} & $\begin{array}{c}\text { Özellik çıkarımı ve destek } \\
\text { vektör makinesi (SVM) } \\
\text { DCGAN ve Siyam Sinir Ağ1 }\end{array}$ & 94,98 \\
Önerilen yöntem & & 98,23 \\
\hline
\end{tabular}

\section{Sonuç}

Bu çalışmada, demiryolu bağlantı elemanlarının incelenmesi için siyam ağı modeli önerilmiştir. Önerilen yöntem, bilgisayarlı görme tabanlı sistemde uygulanmaktadır. Eğitim için sağlam ve deforme bağlantı elemanları kullanılmıştır. Sağlam bağlantı elemanı görüntüleri demiryolundan elde edilen görüntülerden kolayca toplanabilirken deforme bağlantı elemanı görüntülerini bulmak oldukça zordur. Bu nedenle bu çalışmada ilk olarak, DCGAN kullanılarak üretilen yapay deforme bağlantı elemanları görüntüleri sayesinde veri kümesi artırılmıştır. Daha sonra, oluşturulan veri kümesi siyam sinir ağını eğitmek için kullanılmıştır.

Deneysel sonuçlar önerilen yöntemin yüksek hassasiyetini ve verimliliğini göstermektedir. Ayrıca, kusur tespit hassasiyeti sayesinde küçük kusur tespitleri için de kullanılabilir. Veri kümesi farklı sınıflarla genişletilirse, birden çok kusur türünün tespitinde kullanılabilir. Bu çalışmanın nihai hedefleri demiryolunun otomatik denetimi, hızlı inceleme ve işgücü maliyetinin azaltılmasıdır. Bağlantı elemanı hata tespit için siyam sinir ağlarının kullanılması ilgili çalışmaları zenginleştirmektedir.

\section{Teşekkür}

Bu çalışma, 120E097 numaralı TÜBİTAK projesi tarafından desteklenmiştir.

\section{Kaynakça}

[1] Z. Peng, C. Wang, Z. Ma, and H. Liu, "A multifeature hierarchical locating algorithm for hexagon nut of railway fasteners," IEEE Trans. Instrum. Meas., vol. 69, no. 3, pp. 693-699, 2020.

[2] I. Aydin, E. Akin, and M. Karakose, "Defect classification based on deep features for railway tracks in sustainable transportation," Appl. Soft Comput., vol. 111, no. 107706, p. 107706, 2021.

[3] J. Yang, W. Tao, M. Liu, Y. Zhang, H. Zhang, and H. Zhao, "An efficient direction field-based method for the detection of fasteners on high-speed railways," Sensors (Basel), vol. 11, no. 8, pp. 7364-7381, 2011.

[4] H. Ma, "A real time detection method of track fasteners missing of railway based on machine vision," International Journal of Performability Engineering, 2018. 
[5] R. Geirhos, D. H. J. Janssen, H. H. Schütt, J. Rauber, M. Bethge, and F. A. Wichmann, “Comparing deep neural networks against humans: object recognition when the signal gets weaker," arXiv [cs.CV], 2017.

[6] M. Ferguson, R. Ak, Y.-T. T. Lee, and K. H. Law, "Detection and segmentation of manufacturing defects with Convolutional Neural Networks and transfer learning," arXiv [cs.CV], 2018.

[7] J. Shi, Z. Li, T. Zhu, D. Wang, and C. Ni, "Defect detection of industry wood veneer based on NAS and multi-Channel Mask R-CNN," Sensors (Basel), vol. 20, no. 16, p. 4398, 2020.

[8] Y. Yang, X. Zhou, Y. Liu, Z. Hu, and F. Ding, "Wood defect detection based on depth extreme learning machine," Appl. Sci. (Basel), vol. 10, no. 21, p. 7488, 2020.

[9] B. Su, H. Chen, P. Chen, G. Bian, K. Liu, and W. Liu, "Deep learning-based solar-cell manufacturing defect detection with complementary attention network," IEEE Trans. Industr. Inform., vol. 17, no. 6, pp. 4084-4095, 2021.

[10] L. Xu, S. Lv, Y. Deng, and X. Li, “A weakly supervised surface defect detection based on convolutional neural network," IEEE Access, vol. 8, pp. 42285-42296, 2020.

[11] S. Faghih-Roohi, S. Hajizadeh, A. Nunez, R. Babuska, and B. De Schutter, "Deep convolutional neural networks for detection of rail surface defects," in 2016 International Joint Conference on Neural Networks (IJCNN), 2016, pp. 2584-2589.

[12]X. Wei, D. Wei, D. Suo, L. Jia, and Y. Li, "Multi-target defect identification for railway track line based on image processing and improved YOLOv3 model," IEEE Access, vol. 8, pp. 61973-61988, 2020.

[13]H. Cui, J. Li, Q. Hu, and Q. Mao, "Real-time inspection system for ballast railway fasteners based on point cloud deep learning," IEEE Access, vol. 8, pp. 61604-61614, 2020.

[14]T. Bai, J. Yang, G. Xu, and D. Yao, "An optimized railway fastener detection method based on modified Faster R-CNN,” Measurement (Lond.), vol. 182, no. 109742, p. 109742, 2021.

[15] E. Güçlü, İ. Aydin, K. Şahbaz, E. Akin, and M. Karaköse, "Demiryolu bağlantı elemanlarında bulunan kusurların YOLOv4 ve bulanık mantık kullanarak tespiti," Demiryolu Mühendisliği, no. 14, pp. 249262, 2021.

[16] Y. Ou, J. Luo, B. Li, and B. He, "A classification model of railway fasteners based on computer vision," Neural Computing and Applications, 2019.

[17] J. Liu, Y. Teng, X. Ni, and H. Liu, "A fastener inspection method based on defective sample generation and deep convolutional neural network," IEEE Sens. J., vol. 21, no. 10, pp. 12179-12188, 2021.

[18] G. Koch, "Siamese neural networks for one-shot image recognition," Toronto.edu. [Online]. Available: http://www.cs.toronto.edu/ gkoch/files/msc-thesis.pdf. [Accessed: 31-Oct-2021].

[19] M. S. Kim, T. Park, and P. Park, "Classification of steel surface defect using Convolutional Neural Network with few images," in 2019 12th Asian Control Conference (ASCC), 2019, pp. 1398-1401.

[20] S. Wu, Y. Wu, D. Cao, and C. Zheng, "A fast button surface defect detection method based on Siamese network with imbalanced samples," Multimed. Tools Appl., vol. 78, no. 24, pp. 34627-34648, 2019.

[21]A. Nagy and L. Czúni, "Detecting object defects with fusioning convolutional Siamese neural networks," in Proceedings of the 16th International Joint Conference on Computer Vision, Imaging and Computer Graphics Theory and Applications, 2021.

[22] A. Aggarwal, M. Mittal, and G. Battineni, "Generative adversarial network: An overview of theory and applications," International Journal of Information Management Data Insights, vol. 1, no. 1, p. 100004, 2021.

[23]X. Dong et al., "Fast efficient algorithm for enhancement of low lighting video," in 2011 IEEE International Conference on Multimedia and Expo, 2011, pp. 1-6.

[24] K. He, J. Sun, and X. Tang, "Single image haze removal using dark channel prior," IEEE Trans. Pattern Anal. Mach. Intell., vol. 33, no. 12, pp. 2341-2353, 2011.

[25] P. L. Suarez, A. D. Sappa, and B. X. Vintimilla, "Infrared image colorization based on a triplet DCGAN architecture," in 2017 IEEE Conference on Computer Vision and Pattern Recognition Workshops (CVPRW), 2017, pp. 18-23.

[26]I. J. Goodfellow et al., "Generative Adversarial Nets," Neurips.cc. [Online]. Available: https://proceedings.neurips.cc/paper/2014/file/5ca3e9b122f61f8f06494c97b1afccf3-Paper.pdf. [Accessed: 31-Oct-2021].

[27] A. Radford, L. Metz, and S. Chintala, "Unsupervised representation learning with deep convolutional generative adversarial networks," arXiv [cs.LG], 2015.

[28] J. Bromley et al., "Signature verification using a 'Siamese' time delay neural network," Intern. J. Pattern Recognit. Artif. Intell., vol. 07, no. 04, pp. 669-688, 1993.

[29] A. F. Agarap, “Deep Learning using Rectified Linear Units (ReLU),” arXiv [cs.NE], 2018. 
[30]D. P. Kingma and J. Ba, “Adam: A method for stochastic optimization,” arXiv [cs.LG], 2014.

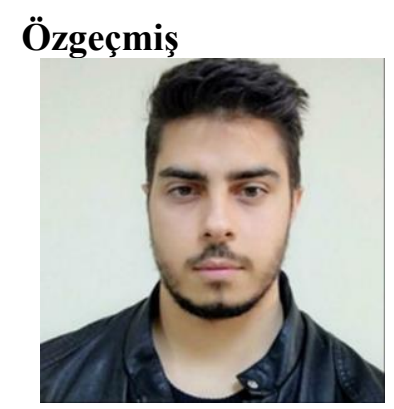

\section{Emre GÜÇLÜ}

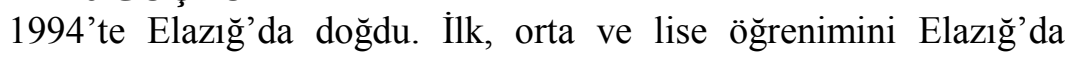
tamamladı. Necip Fazıl Kısakürek Anadolu Lisesi'ni bitirdikten sonra 2019 yılında Fırat Üniversitesi, Mühendislik Fakültesi, Bilgisayar Mühendisliği bölümünden mezun oldu. 2020 yılında Frrat Üniversitesi, Fen Bilimleri Enstitüsü, Bilgisayar Mühendisliği Anabilim dalında yüksek lisans eğitimine başladı. Görüntü işleme ve yapay zekâ alanlarında çalışmalarına devam etmektedir.

E-Posta: emreguclu1367@gmail.com

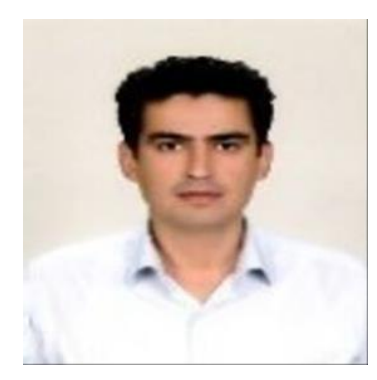

\section{İlhan AYDIN}

1981 yılında Elazığ'da doğdu. Lisans ve Yüksek Lisans derecelerini Fırat Üniversitesi Bilgisayar Mühendisliğinde 2001 ve 2006 yıllarında ald1. Doktora derecesini 2011 y1lında Frrat Üniversitesi, Elazığ Elektrik ve Elektronik Mühendisliği bölümünden aldı.

Halen Fırat Üniversitesi'nde Bilgisayar Mühendisliği bölümünde Doçent olarak görev yapmaktadır. Araştırma alanları arasında optimizasyon, gerçek zamanlı sistemler, hata teşhisi ve durum izleme, sinyal ve görüntü işleme ve derin öğrenme bulunmaktadır.

E-Posta: iaydin@firat.edu.tr

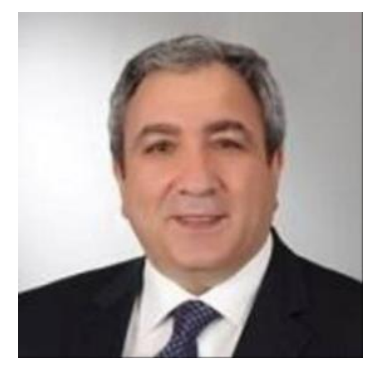

\section{Erhan AKIN}

1963 yılında Erzincan'da doğdu. Elektrik mühendisliği alanında lisans ve yüksek lisans derecelerini ve doktora derecelerini sırasılyla 1984, 1987 ve 1994 yillarında Firat Üniversitesinden aldı. Halen Firat Üniversitesi'nde Bilgisayar Mühendisliği Profesörü olarak görev yapmaktadır. Başlıca araştırma alanları güç elektroniği, değişken hızlı AC sürücülerin dijital kontrolü, bulanık kontrol ve yazılımsal hesaplama teknikleridir.

E-Posta: eakin@firat.edu.tr

\section{Beyanlar:}

Bu makalede bilimsel araştırma ve yayın etiğine uyulmuştur.

Yazarların katkıları: Tüm yazarların eşit katkısı olmuştur. 